\title{
Paperileija olemisen mietiskelynä
}

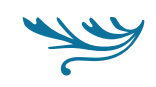

\section{Yrjö Hirnin suomalaisen leikkitutkimuksen perusteoksessa leikki ja taide suhteutuvat elämään oppimismatkana.}

KESÄLLÄ 2OI9 OLIN RETKELLÄ ulkosaaristossa ja törmäsin siellä tapahtumaan, jollaista en ollut nähnyt pitkään aikaan: rantakalliolla oli lapsia aikuisten kanssa lennättämässä leijaa. Näky muistutti minua omasta lapsuudestani.

Katselin leijan kieppumista ilmassa ja narun toisessa päässä rantakalliolla paljain jaloin tepastelevaa lasta. Tunsin, kuinka hänen paljaitten jalkapohjiensa iho painautui vasten auringon lämmittämää kallionpintaa leijanarun kiristyessä. Leija vaikutti itsepäiseltä ja kääntyili uhkaavasti aina välillä kohti veden pintaa, mutta pysyi kuin pysyikin ilmassa pitkään.

Yrjö Hirnin teos Leikkiä ja taidetta (Hirn 1918) on alun perin suunnattu ei-tieteelliselle yleisölle, mutta sitä pidetään ensimmäisenä suomalaisen leikkitutkimuksen perusteoksena. Pohdin Hirnin ajatuksia leikistä ja taiteesta suhteessa elämään oppimismatkana. Minua kiinnostaa se, mitä Hirnin kulttuurihistoriallinen teos on tutkimuksellisesti avannut, mistä se on muistuttanut. Keskityn "Paperileijoista"-lukuun.

HIRNIN TEOS ILMESTYI ensin ruotsin kielellä vuonna 1916 nimellä Barnlek. Sen suomensi kahta vuotta

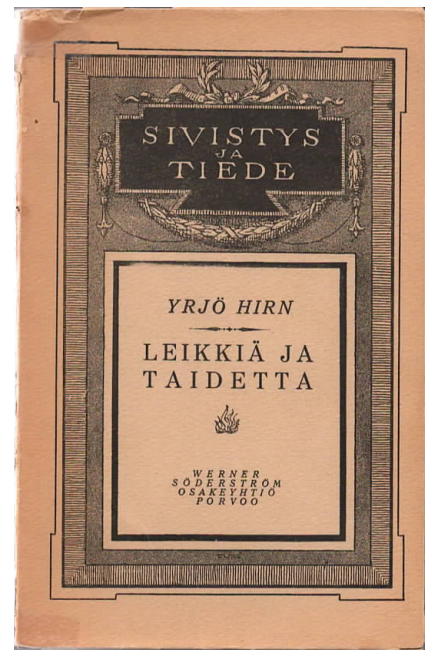

Yrjö Hirnin teos ilmestyi Sivistys ja tiede -kirjasarjassa kustantajanaan WSOY.

myöhemmin J. V. Lehtonen, kirjallisuuden tutkija ja professori, joka tunnettiin myös estetiikan tutkijana. Arvomaailmaltaan Hirnin teksti heijastelee aikaansa. Hän puhuu esimerkiksi "raakalaiskulttuureista", eivätkä tytöt ja naiset hänen mittapuussaan ulotu 


\section{LUENTANI ON}

\section{KASVATUSTIETEILIJ $\ddot{A}$, PEDAGOGIN JA AIKUISEN \\ POHDINTAA.}

poikien ja miesten veroisiksi. Olen lukenut tekstiä välittämättä näistä vanhanaikaisuuksista.

Luen mielelläni tieteenalamme klassikoita, koska niissä puhutaan kasvatuksesta ja kulttuurista kauniisti ja kiinnostavasti: kauniilla kielellä, lämpimällä tunteella ja syvällisin vertauksin. Klassikoista erityisesti ne, joiden kirjoittajilla on vahva estetiikan taju kuten Yrjö Hirnillä, puhuttelevat minua tutkijana. Kiinnostavaa on sekin, kuinka Hirn korostaa taiteen ja leikin välistä läheistä suhdetta, sillä leikki on Hirnin mukaan "kehkeytymätöntä taidetuotantoa".

Yrjö Hirn (1870-1952) oli aikansa tunnetuimpia suomalaisia tiedemiehiä maailmalla. Hän toimi estetiikan professorina Helsingin yliopistossa vuosina 1910-1937. Hirnin erityisalaa olivat estetiikan, kirjallisuuden, kulttuurihistorian ja teatteritieteen alan tutkimus, ja hän oli myös merkittävä Runeberg-tutkija.

Leikkiä ja taidetta -teoksessa paistaa Hirnin syvällinen ja laaja-alainen kulttuurinen tuntemus ja ymmärrys. Hän tarkastelee leikkien ja leikkikalujen lisäksi marionettiteatteria, varjokuvia ja sirkusta. Hannu Riikonen (2003) kirjoittaa Kansallisbiografiassa, kuinka Hirn palasi teoksessaan kadotetun lapsuuden maailmaan nostalgisissa tunnelmissa, sillä erityisesti ensimmäisen maailmansodan aikana hän oli tuntenut itsensä eristyneeksi.

HIRN ARVOSTI leikkikulttuuria itsessään ja ymmärsi sen kytköksen osana kulttuurista jatkumoa. "Paperileijoista"-luvussa hän pohtii kuvittelun ja tunteiden ulottuvuuksia, joita paperileijojen lennättämiseen voidaan liittää. Pohtiessaan leikkiesineitä yhdyssiteinä varhaisten ikävuosien ja aikuisuuden välillä Hirn tuo paperileijan esiin yhtenä esimerkkinä leikkikalujen polveutusmishistoriassa. Olli Sotamaa (2009, 102) toteaa, kuinka sukupolvilta toisille periytyvä leikki voi toimia alakulttuurina, joka kantaa mukanaan sellaisia kulttuurisia elementtejä, jotka muutoin vaipuisivat unohduksiin. Sotamaan käsityksen mukaan Hirn oli tietoinen siitä, miten leikin kautta voidaan tarkastella laajempaa yhteiskunnallista kehitystä ja "tutkia sivistyshistorian sivuteemoja ja akanvirtoja".

Luentani on kasvatustieteilijän, pedagogin ja aikuisen pohdintaa, jossa ajatuksiani tällä kertaa ovat viitoittaneet Johan Fornäsin (1998) kulttuuriteoria, Taneli Tuovisen (2014) Hirnin estetiikan tulkinta sekä Juha Suorannan (2015) huomiot aikuisuudesta ja jatkuvasta oppimisesta.

Fornäs puhuu kulttuurisista prosesseista kommunikatiivisina käytänteinä, joissa on hyvä tarkastella asioiden ja ilmiöiden juuria ja reittejä. Tarkastelemalla juuria eli syitä ja määrittäviä tekijöitä sekä reittejä eli merkityksiä ja vaikutuksia voimme lisätä ymmärrystämme siitä, mistä matkamme koostuu. Symbolien, kuten leijan ja sen lennättämisen, avulla voidaan pohtia mennyttä ja tarkastella tulevaa, sillä symboliset asiat peilaavat ja representoivat sekä erittelevät inhimillisen elämän aspekteja. Symboleissa jokin edustaa jotain muuta. Fornäs (1998) jatkaa, että symbolit yhdistävät sisäisen, subjektiivisen tietoisuuden ulkoisiin, materiaalisiin objekteihin, sillä symbolit saattavat yhteen materiaalisia merkkejä ja subjektienvälisiä merkityksiä.

LEIJA SYMBOLOI Hirnille kasvua, ihmistymistä ja vapautta, koska leijan lennättäminen voi kokemuksena näyttää ja osoittaa yhtä sun toista elämästä, olemisesta ja maailmasta. Hirn $(1918,12)$ ajattelee esineitten itsessään "houkuttelevan erikoisiin mietiskelyihin". Ajatukset erityisistä mietiskelyistä ja paperileijasta luontuvat koskemaan aikuisuutta, ja niitä voi peilata elämään oppimismatkana. Tästä leijan lailla kieppuilevasta matkasta Suoranta $(2015,127)$ toteaa: "Aikuiselämä on tasaisen ja yllätyksettömän elämän sijaan usein erilaisten ongelmien ratkomista ja ristiriitojen yhteen sovittamista sekä oppimista elämään epätäydellisessä maailmassa. Ongelmat ja ristiriidat saattavat syöstä umpikujaan, vetää niin sanotusti maton jalkojen alta, mutta parhaimmillaan niistä tulee tietoisen pohdinnan kohteita ja niitä voi pitää mielekkäinä, ratkottaviksi tarkoitettuina kehitystehtävinä." 


\section{HIRNIN ESTETIIKKAKÄSITYS}

\section{POHJAUTUU LIIKKEEN}

\section{JA TUNTEEN YHTEYDEN \\ YMM ̈̈RT̈̈MISEEN.}

Hirn $(1918,24)$ kirjoittaa oivaltavasti, että "vain katkonaisesti kykenemme saamaan pien aavistuksen kaikista niistä kuvitteluista ja tunteista, jotka ovat liittyneet pieniin leikkikaluihin. Sillä koteutuneena voi vain se liikkua leikkien maailmassa, joka on säilyttänyt keijukaisten sormuksen sormessaan”. Hän korostaa täten lapsenmielisyyttä niin ikään aikuisen elämänasenteessa. Aikuisuuden ei tarvitse tarkoittaa leikkimättä olemista."Paperileija nousee läpi avaruuden, niin korkealle, että lapsen mielikuvitus näkee sen lähestyvän taivaankappaleita2" (Hirn 1918, 42). Leijaa lennättävä miettii kenties, voiko ihminen lentää. Mihin maailma loppuu, mistä taivas alkaa? Mitä elämä on? Mihin me pyrimme?

Hirnin ajatukset ovat avanneet minulle väylän esineiden ja asioiden yhä moniulotteisempaan pohtimiseen ja tuoneet vahvistusta kiinnostuneisuudelleni todellisuuden ilmenemisen tutkailuun ja tutkailemisen tapoihin ihmisen kokemusmaailmassa, kuten juuri taide usein tekee. Hirnin $(1918,59)$ mukaan nimenomaan paperileijalla on "yhtä ja toista kerrottavaa ihmismielen halusta kohota yläpuolelle oman olemuksensa rajoja ja sen värisevästä tuskasta elämän peloittavien mahdollisuuksien edessä3”. Yhtä lailla tämä voi koskettaa niin lapsen kuin aikuisen olemisen rajojen tunnustelemista ja pohdintaa elämästä. Miten kiehtova vapauden ja elämän symboli leija onkaan!

Hirnin mukaan paperileijan kaltaisista yli sukupolvien ja eri kulttuureissa esiintyvistä leikkikaluista osa liittyy vakaviinkin elämäntoimintoihin. Leija on palvellut kulttuureissa uskonnollisia tarkoituksia ja jopa sotaisia. Kiinnostavaa on, että suomeksi 'leija' viittaa leijumiseen, kun taas ruotsiksi drake viittaa alkuperältään lentokäärmeeseen. Käärmeleijoja tavataankin joissain kulttuureissa.
NYKYMAAILMASSA LEIJAT ovat innostaneet monia taiteilijoita, pidän erityisesti kuvataiteilija Jacob Hashimoton tavasta hyödyntää teoksissaan upealla tavalla vanhaa japanilaista paperileijakulttuuria. Samoin mieleeni tulee läheisesti leijoihin liittyvä kirjailija Khaleid Hosseinin teos Leijapoika (2004) ja siitä tehty elokuvaversio vuodelta 2007. Ne kertovat, kuinka afgaanikulttuurissa leijojen lennättäminen oli kulttuurisesti ja yhteisöllisesti tärkeää, kunnes talibanit kielsivät sen turhana ajanhukkana. Hirn olisi todennäköisesti pitänyt tätä merkkinä ihmisen vapauden ja olemisen rajojen tunnustelemisen kahlitsemisesta.

Hirniläisittäin ajateltuna esimerkiksi juuri leija osoittaa, näyttää, kertoo ja vastaa, kuinka mieltä liikuttavat tuntemukset ovat välittömässä vastaavuussuhteessa keholliseen liikkeeseen elintoimintoina, omana liikkuvuutena, yhteyksinä ympäristöön ja toisiin. Se, että leijaa lennättävän jalat tukeutuvat kallion pintaan, leijan naru kiristyy välillä äärimmilleen ja leija halkoo vapaasti ilmaa piirrellen omia kuvioitaan, on merkityksellistä. Tämä perustuu osin Hirnin käsitykseen estetiikasta.

Tuovisen (2014, 46-47) mukaan Hirnin inhimilliseen toimintaan perustuva estetiikkakäsitys pohjautuu liikkeen ja tunteen yhteyden ymmärtämiseen. Hirniläisittäin taiteellisen toiminnan alkuperä on seurattavissa arkisesta työstä ja elämästä tuttuihin käytäntöihin ja maailmasuhteen merkityksiin. Tuovinen toteaa edelleen, että "ihminen on tuntevana oliona alusta asti olemassa avoimena jollekin muulle, jonkin muun kanssa. Siksi ihminen herkkyytensä ja toimintansa muodoissa saa aikaan maailmaansa siinä, missä maailma antaa tämän mahdollisuuden”. Leijan lennättäminen voi olla niin lapselle kuin aikuisellekin kiinnostava maailman aikaan saamisen ja jollekin muulle avoimena olemisen mahdollisuus: kun leija saa tuulta alleen, leijalangan päässä kieppuu ja kääntyilee jotakuinkin ennalta ohjailematon elämä.

Hirnin estetiikasta ja kehollisuudesta Tuovinen $(2014,54)$ toteaa: "Hirn käy hyvin yksityiskohtaisesti läpi, kuinka mieltä liikuttavat tuntemukset ovat välittömässä vastaavuussuhteessa keholliseen liikkeeseen elintoimintoina, omana liikkuvuutena, yhteyksinä ympäristöön ja toisiin. Keholliset ja arkiset 
yhteytemme liikkeessä aiheuttavat tajuntaa virittäviä konteksteja, ikään kuin pyrkimyskenttiä. Näiden suuntaamina me koko ajan tähtäämme poistamaan epäsuotuisten tuntemusten aiheuttamaa estyneisyyttä, puutumista, epäselvyyttä tai tukemaan suotuisien, vapautuneisuuteen ja selkeyteen johtavien tuntemusten virvoittavuutta."

LEIJAN LENNÄTTÄMINEN on kehollinen ja leikillinen elämän tutkailemisen tapahtuma, johon sisältyy mahdollisuus vapauden tunnustelemiseen. Toisinaan leijan naru voi mennä solmuunkin tai leija päästä karkuun: "Päinvastoin oppimisen ja kehittymisen näkökulmasta aikuiselämä pitää sisällään paitsi näennäisen tyhjiä kausia myös niin hurjia jaksoja, että oppimiskokemusten takkuisia solmuja on mahdollista avata vasta jälkeenpäin, jos silloinkaan. Samalla tavoin kuin kokemus karttuu ja kehittyy myönteisen progressiivisesti, se voi myös kiertyä taaksepäin rullalle ja olla merkki regressiivisestä paluusta ehkä hyvinkin kauas omaan menneisyyteen." (Suoranta 2015, 137.)

On kiehtova ajatus, että leijan lennättämiseen liittyy elämän olemisen mietiskelyä, pyrkimyksiä johonkin. Eikö meidän kannattaisi laajemminkin tarkastella ympäristöämme, esineistöä ja materiaaleja siinä sekä ylipäätään elämänmittaisia kasvuympäristöjämme kulttuurisina ja esteettisinä käytäntöinä, joissa esineiden ja olioiden juurilla ja reiteillä on merkitystä elämään kasvussa?

Miten esimerkiksi ajatus opetuksesta muuttuisi, jos huomioisimme niin lasten kuin aikuistenkin kiinnostumiset symbolisina peilaamisina, representoimisina ja erittelemisinä, kehkeytyvinä tapahtumina, joissa jokin sisäinen yhdistyy materiaalisiin objekteihin tai löytää reittinsä ulos niiden kautta? Ei vain jatkuvan, eksponentiaalisen kasvun ja kehityksen periaatteella, vaan yhtä lailla poukkoilemisina ja takapakkeina. Siteeraan jälleen Suorantaa $(2015,127)$ : "Toinen tärkeä oivallus syntyy, kun aikuisuuden ymmärtää jatkuvana oppimisena ja kehittymisenä, jota moninaiset itseen kohdistuvat psyykkiset kehitysprosessit ja itsen ulkopuoliset sosiaaliset suhteet vuoroin hidastavat ja vuoroin jouduttavat." Arkipäivän huomaamatonkin tai tavanomainen voi sisältää enemmän merkityksiä kuin arvaammekaan.

Leikkiä ja taidetta muistuttaa minua siitä, miten erilaiset esineet, materiaalit, ilmiöt, toiminnot ja ympäristöt itsessään voivat houkutella erityisiin mietiskelyihin. Osaammeko antaa tälle mahdollisuutta? Onko meillä aikaa mietiskelyille, leikille ja taiteelle? Onko nykyihminen erkaantumassa kehollisista kokemuksista, tunteen ja liikkeen yhteydestä vai edistääkö esimerkiksi teknologia sitä? Kuinka nykykasvatus mahdollistaa elämän tunnustelemisen esimerkiksi kaipuun tai haaveilemisen viettinä?

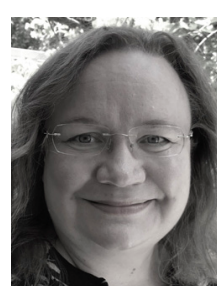

\section{SARA SINTONEN}

MuT, dosentti, yliopistonlehtori kasvatustieteellinen tiedekunta Helsingin yliopisto

\footnotetext{
${ }^{1}$ Teoksen käännöksen tarkastelussa minua auttoi tutkijakollegani Alexandra Nordström, jonka kanssa kävimme läpi teoksen kohtia lukien sitä rinnan ruotsin ja suomen kielellä. Vrt. 'erikoisiin' (ruots. specifika, erityisiin), eli tarkempi suomennos kuuluisi "houkuttelevan erityisiin mietiskelyihin".

${ }^{2}$ Vrt. 'lapsen mielikuvitus' (ruots. barnslik fantasi, lapsenomainen kuvittelu), eli tarkempi suomennos kuuluisi "Paperileija nousee läpi avaruuden, niin korkealle, että lapsenomainen kuvittelu näkee sen lähestyvän taivaankappaleita".

${ }^{3}$ Vrt. 'halusta' (ruots. begär, himo) sekä 'elämän' (ruot. tillvaro, olemisen), eli tarkempi suomennos kuuluisi "yhtä ja toista kerrottavaa ihmismielen himosta kohota yläpuolelle oman olemuksensa rajoja ja sen värisevästä tuskasta olemisen peloittavien mahdollisuuksien edessä".
}

Klassikon paluu -sarjassa esitellään teoksia, jotka ovat olleet merkityksellisiä aikuiskasvatuksen tutkijoille ja ammattilaisille opinnoissa, tutkimuksessa ja työssä. 
LÄHTEET

Fornäs, J. (1998). Kulttuuriteoria. Suomentanut M. Lehtonen ym. Tampere: Vastapaino.

Hirn, Y. (1918). Leikkiä ja taidetta: Muutamia lukuja lasten leluista, lauluista, tansseista ja pikku teatterista, Suomentanut J. V. Lehtonen. WSOY.

Riikonen, H. K. (2003). Hirn, Yrjö. Kansallisbiografiaverkkojulkaisu. Studia Biographica 4. Helsinki: Suomalaisen Kirjallisuuden Seura, 1997-. http://urn.fi/ urn:nbn:fi:sks-kbg-000704 . (3.5.2020).

Sotamaa, O. (2009). Suomalaisen pelitutkimuksen monet alut. Teoksessa J. Suominen, R. Koskimaa, F. Mäyrä \& O. Sotamaa (toim.) Pelitutkimuksen vuosikirja 2009, 100-105. http://www.pelitutkimus.fi/vuosikirja2009/ ptvk2009-kaikki.pdf (3.10.2019).
Suoranta, J. (2015). Merkittävät oppimiskokemukset rannalla. Teoksessa M. Hyvärinen, E. Oinonen \& T. Saari (toim.). Hajoava perhe: romaani monitieteisen tutkimuksen välineenä. Tampere: Vastapaino.

Tuovinen, T. (2014). Taide ennen taidetta sellaisena kuin sen tunnemme - Yrjö Hirnin matkassa taiteen alkulähteille. Teoksessa E. Heikkilä \& T. Tuovinen (toim). Uusi taidekasvatusliike, 45-64. https:// aaltodoc.aalto.fi/bitstream/handle/123456789/15431/ isbn9789526059662. pdf? sequence=1\&isAllowed= (3.10.2019).

\section{Allekirjoita digitointilupa}

Aikuiskasvatus-tiedelehti digitoidaan koko julkaisuhistorialtaan, vuodesta1981 lähtien. Sen jälkeen vanhatkin numerot ovat ilmaiseksi luettavissa Journal.fipalvelussa.

Jos olet kirjoittanut Aikuiskasvatus-tiedelehteen ennen vuotta 2019, allekirjoita verkossa lupa digitoida kirjoituksesi. Samalla voit antaa asiasanat tekstiisi: bit.ly/aikuiskasvatuksen_digitointilupa 